\title{
lodised salt contribution to iodine nutrition status of pregnant and lactating women
}

\author{
Haihong Zhang ${ }^{1} \dagger$, Shengmin $\mathrm{Lv}^{2 *} \dagger$, Zhenguo $\mathrm{Mu}^{3}$, Weihong $\mathrm{Li}^{1}$, Xia Zhang ${ }^{4}$, Yuchun Wang ${ }^{5}$ and \\ Shannon Rutherford ${ }^{6}$ \\ ${ }^{1}$ Shijiazhuang Municipal Center for Disease Prevention and Control, Shijiazhuang, People's Republic of China \\ ${ }^{2}$ Hebei Province Center for Disease Prevention and Control, No. 97, Huai'an Donglu, Shijiazhuang, Hebei Province O50021, \\ People's Republic of China \\ ${ }^{3}$ Shijiazhuang Municipal Bureau of Food and Drug Administration, Shijiazhuang, People's Republic of China \\ ${ }^{4}$ Chang'an District Center for Disease Prevention and Control, Shijiazhuang, People's Republic of China \\ ${ }^{5}$ Hengshui Municipal Center for Disease Prevention and Control, Hengshui, People's Republic of China \\ ${ }^{6}$ Centre for Environment and Population Health, School of Environment, Griffith University, Brisbane, QLD, Australia \\ (Submitted 14 January 2015 - Final revision received 7 April 2015 - Accepted 13 April 2015 - First published online 10 June 2015)
}

\section{Abstract}

Sufficient iodine intake by pregnant and lactating women is crucial to their offspring's cognitive development. The aim of the present study was to explore the impact of iodised salt intake on the iodine status of pregnant and lactating women. Thirty towns were selected from 211 towns in the rural areas of Shijiazhuang city using probability proportionate to size sampling in this cross-sectional survey. In each selected town, forty pregnant women and forty lactating women were randomly selected to contribute urine samples to determine iodine content. The median urinary iodine content (UIC) of 1200 pregnant women in all was 146 (interquartile range (IQR) 88-239) $\mu \mathrm{g} / \mathrm{l}$. The median UIC in the first, second and third trimesters were 166 (IQR 92-276) $\mu \mathrm{g} / \mathrm{l}, 145$ (IQR 83-248) $\mu \mathrm{g} / \mathrm{l}$ and 134 (IQR 79-221) $\mu \mathrm{g} / \mathrm{l}$, respectively. The median UIC in the first trimester was significantly higher than that in the third trimester $(P=0 \cdot 04)$. The median UIC of 1200 lactating women in all was 120 (IQR 66-195) $\mu \mathrm{g} / \mathrm{l}$. Their median UIC in every 4-week block was higher than the WHO criteria except in weeks $25-28$ and weeks 33-36 of lactation. Pregnant women's median UIC did not correlate with median salt iodine (MSI) $(P=0 \cdot 402)$; however, there was a linear correlation between MSI and the lactating women's median UIC $(P=0 \cdot 007)$. Iodised salt failed to provide adequate iodine to pregnant women possibly due to limited intake of iodised salt during pregnancy, though it was found to provide adequate iodine to lactating women in the rural areas of Shijiazhuang city.

Key words: Iodine deficiency: Urinary iodine: Pregnancy: Lactation

Iodine deficiency is currently the leading preventable cause of mental retardation worldwide ${ }^{(1)}$. Insufficient thyroid hormone is the main cause of iodine deficiency disorders (IDD). The most notable effects of iodine deficiency are its impacts on brain development, which mainly occur in utero and in early life ${ }^{(2)}$, leading to stunted intelligence in children. The most extreme form of these impacts is cretinism which is caused by severe iodine deficiency ${ }^{(3)}$, but the subtler degrees of brain damage and reduced cognitive capacity which affect the entire population imply a severe public health crisis $^{(4)}$. A few studies have confirmed that even mild iodine deficiency during pregnancy could result in cognitive deficits in the offspring $^{(5-7)}$. The most critical period of brain development of the human child is from the first trimester of pregnancy to the third year after birth ${ }^{(8,9)}$. Therefore, sufficient iodine intake by pregnant and lactating women is crucial to their offspring's brain development. It is well acknowledged that pregnant and lactating women are important target population for the successful management of IDD.

The WHO recommends universal salt iodisation (USI) as the main measure to supplement iodine to populations at risk of iodine deficiency ${ }^{(4)}$. This strategy has been implemented around the world and has achieved great success ${ }^{(10)}$. However, due to the increased demand for iodine during

Abbreviations: CDC, Center for Disease Prevention and Control; IDD, iodine deficiency disorders; IQR, interquartile range; MSI, median salt iodine; MWI, median water iodine; UIC, urinary iodine content; USI, universal salt iodisation.

*Corresponding author: S. Lv, fax +8631186573440, email 1sm6810@163.com

† Haihong Zhang and Shengmin Lv are joint first authors. 
pregnancy $^{(11)}$ and lactation ${ }^{(12)}$, a number of studies have indicated that while USI can provide adequate iodine for general populations, it is not sufficient for pregnant women ${ }^{(13-16)}$. Given the convenience of conducting surveys using school children, it is a conventional practice in China that the median urinary iodine content (UIC) in children aged 8-10 years is used as the indicator to evaluate the iodine nutrition status of the whole population including pregnant and lactating women. However, one study has suggested that children's median UIC does not sufficiently represent the iodine nutrition of pregnant and lactating women, since the study found that the median UIC in children aged 8-10 years was $50 \mu \mathrm{g} / 1$ higher than that of pregnant women, and was $40 \mu \mathrm{g} / 1$ higher than that of lactating women ${ }^{(17)}$. Hence, direct monitoring of the iodine status of pregnant and lactating women is necessary for ensuring healthier children.

Iodine deficiency is predominantly related to naturally occurring low iodine content in underground water and soil $^{(9)}$. The Chinese criterion for classification of a region as iodine deficient is characterised by an iodine content in its underground water below $10 \mu \mathrm{g} / \mathrm{l}$. Shijiazhuang city, the capital of Hebei province, is located in the middle of the Hebei plain. It administers five districts and eighteen counties and has a population of over 10 million. Iodine deficiency prevailed in the rural areas of this city in the past, with half of the eighteen counties identified as endemic areas of IDD in the early 1980s. A study conducted in 2009 in the city indicated that the median UIC of children aged 8-10 years reached $211 \mu \mathrm{g} / 1$ (which suggests more than adequate iodine intake based on the WHO criteria) following the implementation of USI for 14 years $^{(18)}$. However, the iodine nutrition status of pregnant and lactating women in the city has not been investigated and remains unclear. The present study was a comprehensive survey on the iodine status of pregnant and lactating women conducted in thirty towns of Shijiazhuang city, of Hebei province. Its aim was to examine the effectiveness of iodised salt in supplementing iodine nutrition in these two focus populations and to identify potential problems if any in their iodine nutrition in order to facilitate the most appropriate intervention measures in the future.

\section{Materials and methods}

\section{Sampling method and data collection}

Selection of towns and collection of urine and edible salt samples. Probability proportional to size sampling is a commonly used design in multistage cluster sampling, in which the probability of a particular sampling unit selected is proportional to the population size of the sampling unit ${ }^{(10)}$. It was the probability proportional to size sampling design that was employed in the present cross-sectional survey. If a salt iodisation programme has been implemented for some years, and if goitre rates are likely to be about $5 \%$, a relative precision of $30 \%$ may be adequate ${ }^{(19)}$ for a study. The design effect for this cluster sampling was established at three. According to the equation for calculating sample size, the total sample size for this survey was about $1200^{(19)}$. As the cluster was set at thirty, the sample size for each cluster was forty. With township as the sampling unit (cluster), thirty towns were selected first from 211 towns. From each of the towns selected, forty pregnant and forty lactating women were randomly selected according to the registration of pregnancy and delivery in the township hospital. Only healthy pregnant and lactating women without thyroid-related diseases were included in the present study. Their spot urine samples and edible salt samples were collected at their residences.

Collection of drinking water samples. Since the drinking water supply in the countryside of Shijiazhuang city was centralised (tap water), it was not necessary to collect samples individually from every participant's house. Based on previous studies, it was found that the iodine content in the drinking water in the rural area of Shijiazhuang city was low (most samples were under $10 \mu \mathrm{g} / \mathrm{l}$ ), and varied little. Hence, we used the overall median water iodine (MWI) of the town to represent the iodine content of the drinking water at a participant's house. Therefore, in each selected town, drinking water samples were collected at each village where the participants lived. The number of drinking water samples collected depended on the number of villages.

All samples were collected by well-trained endemic control staff of the local county Center for Disease Prevention and Control (CDC). The samples were kept below $4^{\circ} \mathrm{C}$, and then transported to the IDD laboratory of Shijiazhuang Municipal CDC for iodine content determination. This laboratory is accredited by the National IDD Reference Laboratory for iodine detection in water, salt and urine.

The survey was approved by the Shijiazhuang Municipal Bureau of Science and Technology. Written consent for collection of urine, drinking water and salt samples were obtained from the participants involved. The survey was conducted in September 2012.

\section{Laboratory measurement and data analysis}

lodine in urine samples. The iodine content of urine samples was measured by the method of Sandell-Kolthoff reaction in the Shijiazhuang municipal CDC laboratory ${ }^{(20)}$. Urinary iodine values from populations are generally not normally distributed, hence the median rather than the mean is recommended as the measure of central tendency by the WHO. The WHOrecommended median UIC for pregnant women is between 150 and $250 \mu \mathrm{g} / \mathrm{l}$, and for lactating women, above $100 \mu \mathrm{g} / \mathrm{l}^{(10)}$.

lodine in edible salt and drinking water samples. The iodine content of salt was determined quantitatively using a titration method in Shijiazhuang municipal CDC laboratory ${ }^{(21)}$. According to the latest provincial document (2012) for iodine concentration in iodised salt, the adequate iodine content is set at $18-50 \mathrm{mg} / \mathrm{kg}$. Iodised salt with iodine content that falls within this range is classified as qualified, and salt with iodine content outside this range is classified as unqualified. According to the national criteria for iodised salt, the rate of adequate iodisation at the household level should be more than $90 \%{ }^{(22)}$.

The iodine content in drinking water was determined by the method of arsenic-cerium oxidation-reduction spectrophotometry in Shijiazhuang municipal CDC laboratory ${ }^{(23)}$. 
Based on the Chinese national criterion for classification of iodine deficiency areas, drinking water with iodine content less than $10 \mu \mathrm{g} / \mathrm{l}$ is classified as iodine deficient ${ }^{(24)}$.

Data processing and statistical analysis. Data processing and statistical analyses were performed using statistical software packages Epi-Info ${ }^{\text {тм }} 2002$ (CDC) and SPSS version 13.0 (SPSS, Inc.). Since the distributions of iodine in edible salt, drinking water and urine were not normal, the median was employed to describe their central tendency. The interquartile range (IQR, 25-75\%) was applied to describe their variations. The differences in pregnant women's median UIC among three trimesters was tested using the Kruskal-Wallis test. The Mann-Whitney test was employed to test the differences in median UIC between any two of the three trimesters. The changes in pregnant women's UIC across every 4-week period from conception was analysed by LOESS (locally weighted scatterplot smoothing) analysis. The one-sample Kolmogorov-Smirnov test was employed to examine the distribution of pregnant and lactating women's median UIC and median salt iodine (MSI). The association between the pregnant and lactating women's median UIC and MSI was analysed using linear correlation. The above two items of analysis were performed on the cluster median. A linear regression model was developed after identifying variables that had a significant linear correlation. Finally, the $R^{2}$ value for the linear regression model was used to present the contribution that the independent variable makes to the variability in the dependent variable.

\section{Results}

\section{lodine content in drinking water and edible salt}

A total of 478 drinking water samples were collected from the residences of pregnant women in the thirty rural town areas of Shijiazhuang city. The overall MWI was found to be $5 \mu \mathrm{g} / \mathrm{l}$, with an overall IQR of $4-8 \mu \mathrm{g} / \mathrm{l}$. A total of 501 drinking water samples were collected from the residences of lactating women in the thirty towns. The overall MWI was $4 \mu \mathrm{g} / \mathrm{l}$, with an IQR of $3-7 \mu \mathrm{g} / \mathrm{l}$. The MWI in each of the thirty towns in rural areas of Shijiazhuang city for both groups of women is provided in Table 1.

A total of 1200 edible salt samples were collected from the residences of each sample of pregnant and lactating women in the thirty rural town areas of Shijiazhuang city. The overall MSI for pregnant and lactating women in the thirty towns was $27 \cdot 2 \mathrm{mg} / \mathrm{kg}$ with an IQR of $23.5-31.7 \mathrm{mg} / \mathrm{kg}$ and $27.9 \mathrm{mg} / \mathrm{kg}$ with an IQR of $24.7-31.0 \mathrm{mg} / \mathrm{kg}$, respectively. The MSI for pregnant and lactating women in the thirty towns varied

Table 1. lodine content in drinking water at the residences of pregnant and lactating women in thirty towns in the rural areas of Shijiazhuang city, September 2012

(Medians and interquartile ranges (IQR, 25-75\%))

\begin{tabular}{|c|c|c|c|c|c|c|}
\hline \multirow[b]{2}{*}{ Town } & \multicolumn{3}{|c|}{ Pregnant } & \multicolumn{3}{|c|}{ Lactating } \\
\hline & Water samples & MWI $(\mu \mathrm{g} / \mathrm{l})$ & IQR $(\mu \mathrm{g} / \mathrm{l})$ & Water samples & MWI $(\mu \mathrm{g} / \mathrm{l})$ & IQR $(\mu \mathrm{g} / \mathrm{l})$ \\
\hline Zhengding & 12 & 8 & $5-11$ & 14 & 6 & $3-10$ \\
\hline Tianchang & 19 & 2 & $1-5$ & 16 & 3 & $2-5$ \\
\hline Ciyu & 14 & 8 & $4-12$ & 17 & 7 & $4-11$ \\
\hline Yanchuan & 23 & 6 & $5-10$ & 19 & 6 & $4-9$ \\
\hline Xiulin & 9 & 2 & $1-5$ & 13 & 3 & $2-6$ \\
\hline Lingshou & 16 & 7 & $5-11$ & 21 & 8 & $6-10$ \\
\hline Gaoyi & 13 & 6 & $4-9$ & 11 & 5 & $3-8$ \\
\hline Gangnan & 21 & 5 & $2-8$ & 23 & 4 & $2-7$ \\
\hline Nanliu & 17 & 3 & $1-7$ & 19 & 4 & $2-9$ \\
\hline Beisu & 15 & 5 & $2-10$ & 12 & 6 & $3-9$ \\
\hline Wentang & 20 & 6 & $1-8$ & 16 & 5 & $2-7$ \\
\hline Yuanshi & 11 & 5 & $3-6$ & 17 & 5 & $3-8$ \\
\hline Xiaojue & 17 & 3 & $1-5$ & 20 & 4 & $2-8$ \\
\hline Xinji & 14 & 4 & $3-9$ & 18 & 5 & $3-8$ \\
\hline Gaocheng & 10 & 3 & $2-5$ & 13 & 3 & $2-6$ \\
\hline Dahe & 18 & 2 & $1-3$ & 21 & 3 & $2-5$ \\
\hline Yian & 15 & 3 & $2-7$ & 12 & 4 & $2-8$ \\
\hline Jinzhou & 12 & 5 & $4-9$ & 16 & 4 & $3-8$ \\
\hline Zhaowei & 16 & 4 & $3-7$ & 11 & 5 & $3-9$ \\
\hline Koutou & 22 & 5 & $4-7$ & 17 & 5 & $4-10$ \\
\hline Chengzhai & 19 & 4 & $2-8$ & 22 & 4 & $3-7$ \\
\hline Zhaozhou & 14 & 7 & $6-11$ & 19 & 6 & $4-9$ \\
\hline Shahe & 18 & 8 & $7-9$ & 13 & 7 & $6-10$ \\
\hline Xingguo & 11 & 5 & $4-9$ & 19 & 4 & $3-7$ \\
\hline Zhangleng & 17 & 5 & $3-7$ & 12 & 6 & $5-11$ \\
\hline Xinji & 13 & 4 & $2-6$ & 14 & 5 & $3-9$ \\
\hline Tianzhuang & 16 & 5 & $2-9$ & 16 & 6 & $3-11$ \\
\hline Yuanshi & 23 & 5 & $3-6$ & 20 & 4 & $3-8$ \\
\hline Shenze & 15 & 6 & $3-11$ & 19 & 8 & $4-10$ \\
\hline Lianzhou & 18 & 4 & $1-8$ & 21 & 5 & $3-9$ \\
\hline Total & 478 & 5 & $3-8$ & 501 & 4 & $3-7$ \\
\hline
\end{tabular}

MWI, median water iodine. 
Table 2. lodine content in iodised salt at the residences of the pregnant and lactating women in thirty towns in the rural area of Shijiazhuang city, September 2012

(Medians and interquartile ranges (IQR, 25-75\%))

\begin{tabular}{|c|c|c|c|c|}
\hline \multirow[b]{2}{*}{ Town } & \multicolumn{2}{|c|}{ Pregnant } & \multicolumn{2}{|c|}{ Lactating } \\
\hline & $\begin{array}{c}\mathrm{MSI} \\
(\mathrm{mg} / \mathrm{kg})\end{array}$ & $\begin{array}{c}\text { IQR } \\
(\mathrm{mg} / \mathrm{kg})\end{array}$ & $\begin{array}{c}\mathrm{MSI} \\
(\mathrm{mg} / \mathrm{kg})\end{array}$ & $\begin{array}{c}\text { IQR } \\
(\mathrm{mg} / \mathrm{kg})\end{array}$ \\
\hline Zhengding & $28 \cdot 9$ & $27 \cdot 3-32 \cdot 4$ & $29 \cdot 7$ & $28 \cdot 3-31 \cdot 3$ \\
\hline Tianchang & $25 \cdot 6$ & $24 \cdot 1-27 \cdot 1$ & $25 \cdot 1$ & $20 \cdot 9-29 \cdot 3$ \\
\hline Ciyu & $26 \cdot 1$ & $22.9-29.9$ & $25 \cdot 7$ & $21 \cdot 3-28 \cdot 1$ \\
\hline Yanchuan & $30 \cdot 2$ & $24 \cdot 6-33 \cdot 6$ & 33.5 & $32 \cdot 1-36 \cdot 5$ \\
\hline Xiulin & 29.4 & $27 \cdot 2-33 \cdot 1$ & $28 \cdot 6$ & $25 \cdot 4-32 \cdot 4$ \\
\hline Lingshou & $31 \cdot 2$ & $23.5-33.6$ & 28.9 & $27 \cdot 3-29 \cdot 7$ \\
\hline Gaoyi & 26.5 & $22 \cdot 9-32 \cdot 0$ & $27 \cdot 7$ & $25 \cdot 4-30 \cdot 0$ \\
\hline Gangnan & $26 \cdot 9$ & $22 \cdot 9-29 \cdot 3$ & $28 \cdot 1$ & $25 \cdot 2-30 \cdot 4$ \\
\hline Nanliu & 30.6 & $23 \cdot 4-33 \cdot 2$ & 28.9 & $27 \cdot 3-31 \cdot 2$ \\
\hline Beisu & 25.4 & $22 \cdot 1-26 \cdot 5$ & $27 \cdot 7$ & $24.3-31.5$ \\
\hline Wentang & $23 \cdot 8$ & $20 \cdot 0-26 \cdot 9$ & $27 \cdot 8$ & $25 \cdot 4-31 \cdot 1$ \\
\hline Yuanyi & 28.4 & $27 \cdot 6-30 \cdot 0$ & $23 \cdot 1$ & $21 \cdot 5-24 \cdot 4$ \\
\hline Xiaojue & $24 \cdot 7$ & $23 \cdot 9-27 \cdot 4$ & $23 \cdot 6$ & $21 \cdot 0-26 \cdot 9$ \\
\hline Xinji & $31 \cdot 0$ & $26 \cdot 0-35.5$ & 33.9 & $31 \cdot 0-35 \cdot 6$ \\
\hline Gaocheng & $23 \cdot 9$ & $22 \cdot 9-25 \cdot 1$ & $26 \cdot 8$ & $26 \cdot 1-27 \cdot 9$ \\
\hline Dahe & $32 \cdot 6$ & $29 \cdot 8-35 \cdot 1$ & $29 \cdot 3$ & $25 \cdot 0-32 \cdot 5$ \\
\hline Yian & $26 \cdot 3$ & $24 \cdot 2-32 \cdot 4$ & 30.5 & $28 \cdot 8-32 \cdot 6$ \\
\hline Jinzhou & $27 \cdot 7$ & $22 \cdot 4-31 \cdot 8$ & $26 \cdot 5$ & $25 \cdot 8-27 \cdot 9$ \\
\hline Zhaowei & $25 \cdot 8$ & $23.4-29.0$ & $27 \cdot 1$ & $24.0-33.5$ \\
\hline Koutou & $26 \cdot 9$ & $22 \cdot 6-31 \cdot 8$ & $23 \cdot 8$ & $22 \cdot 4-26 \cdot 7$ \\
\hline Chengzhai & $27 \cdot 1$ & $20.9-31.9$ & 23.5 & $21 \cdot 9-25 \cdot 6$ \\
\hline Zhaozhou & $23 \cdot 4$ & $20 \cdot 9-24 \cdot 6$ & $27 \cdot 9$ & $25 \cdot 7-28 \cdot 8$ \\
\hline Shahe & $25 \cdot 3$ & $20.9-29.6$ & $28 \cdot 6$ & $23 \cdot 2-33 \cdot 1$ \\
\hline Xingguo & $26 \cdot 1$ & $22.5-30.9$ & 28.4 & $25 \cdot 7-29 \cdot 2$ \\
\hline Zhangleng & 32.6 & $32 \cdot 6-36 \cdot 4$ & 29.4 & $27 \cdot 1-31 \cdot 3$ \\
\hline Xinji & 29.3 & $25 \cdot 6-31 \cdot 2$ & $26 \cdot 8$ & $25 \cdot 8-28 \cdot 8$ \\
\hline Tianzhuang & $26 \cdot 7$ & $22 \cdot 2-29 \cdot 6$ & $24 \cdot 6$ & $22 \cdot 2-27 \cdot 0$ \\
\hline Yuanshi & $26 \cdot 8$ & $24 \cdot 1-29 \cdot 6$ & 30.5 & $22 \cdot 4-31 \cdot 3$ \\
\hline Shenze & $30 \cdot 7$ & $27 \cdot 4-35 \cdot 8$ & $32 \cdot 6$ & $31 \cdot 7-36 \cdot 2$ \\
\hline Lianzhou & $26 \cdot 2$ & $24.9-28.3$ & $30 \cdot 1$ & $25 \cdot 2-33 \cdot 1$ \\
\hline Total & $27 \cdot 2$ & $23.5-31.7$ & $27 \cdot 9$ & $24 \cdot 7-31 \cdot 0$ \\
\hline
\end{tabular}

$\mathrm{MSI}$, median salt iodine.

from 23.4 to $32.6 \mathrm{mg} / \mathrm{kg}$ and 23.1 to $33.9 \mathrm{mg} / \mathrm{kg}$, respectively. The overall rate of adequately iodised salt in the thirty towns was $95.8 \%$. The MSI for both groups in each of the thirty rural town areas of Shijiazhuang city is shown in Table 2.

\section{lodine content in urine samples of pregnant women}

A total of 1200 urine samples from pregnant women were collected and measured for iodine content, with the median UIC being 146 (IQR 88-239) $\mu \mathrm{g} / \mathrm{l}$. The percentages of urine samples with iodine content $<150,150-250,>250 \mu \mathrm{g} / \mathrm{l}$ were $51 \cdot 6 \%(619 / 1200), 23 \cdot 0 \%(276 / 1200)$ and $25 \cdot 4 \%(305 /$ 1200), respectively.

The median UIC of pregnant women in the first, second and third trimesters were 166 (IQR 92-276) $\mu \mathrm{g} / 1,145$ (IQR 83248) $\mu \mathrm{g} / \mathrm{l}$ and 134 (IQR 79-221) $\mu \mathrm{g} / \mathrm{l}$, respectively. There was no statistically significant difference among the median UIC across trimesters (Kruskal-Wallis test, $\chi^{2}=4.33$, $P=0 \cdot 12$ ). Nevertheless, pairwise comparisons of median UIC between any two of the three trimesters, found that the pregnant women's median UIC in the first trimester was significantly higher than that in the third trimester
(Mann-Whitney test, $U=18265, \quad P=0 \cdot 04)$. The median UIC of pregnant women in each trimester and the IQR are listed in Table 3.

In order to explore the monthly changes of pregnant women's median UIC during pregnancy, their median UIC for every 4 weeks starting from conception was analysed by LOESS analysis. The obtained smoothed line was slightly curved, lower in the middle and higher at both ends. The LOESS analysis is displayed in Fig. 1.

\section{lodine content in urine samples of lactating women}

A total of 1200 urine samples of lactating women whose breastfeeding duration ranged from 1 to 80 weeks were collected and measured for iodine content, with the median UIC being 120 (IQR 66-195) $\mu \mathrm{g} / \mathrm{l}$. The percentages of urine samples with iodine content above and below $100 \mu \mathrm{g} / \mathrm{l}$ (the WHO's threshold of adequate iodine intake for lactating women) were $59 \cdot 1 \%$ (709/1200) and 40.9\% (491/1200), respectively.

Lactating women's median UIC for every 4 weeks starting from the 1 st week to the 88th week of lactation were calculated and are displayed in Fig. 2. Because of insufficient urine samples (less than thirty samples, which is suggested by $\mathrm{WHO}^{(10)}$ as sufficient sample size for evaluating the iodine nutrition status in a given population) collected for every 4-week block after week 41, lactating women's median UIC was calculated in the intervals during which the numbers of urine samples exceeded thirty, i.e. weeks 41-46, weeks 47-53, weeks 54-61 and weeks 62-88. Lactating women's median UIC for every 4-week period in the first year of lactation (53 weeks) was higher than the WHOrecommended criterion $(100 \mu \mathrm{g} / \mathrm{l})$ except for weeks $25-28$ and weeks 33-36. The median UIC in weeks 1-4 was remarkably higher than those in the rest, reaching $187 \mu \mathrm{g} / \mathrm{l}$. The median UIC appeared to rise after week 47 of lactation. It rose from $131 \mu \mathrm{g} / 1$ during weeks $47-53$ to $147 \mu \mathrm{g} / \mathrm{l}$ during weeks 54-61. However, it fell back to $129 \mu \mathrm{g} / 1$ during weeks 62-88.

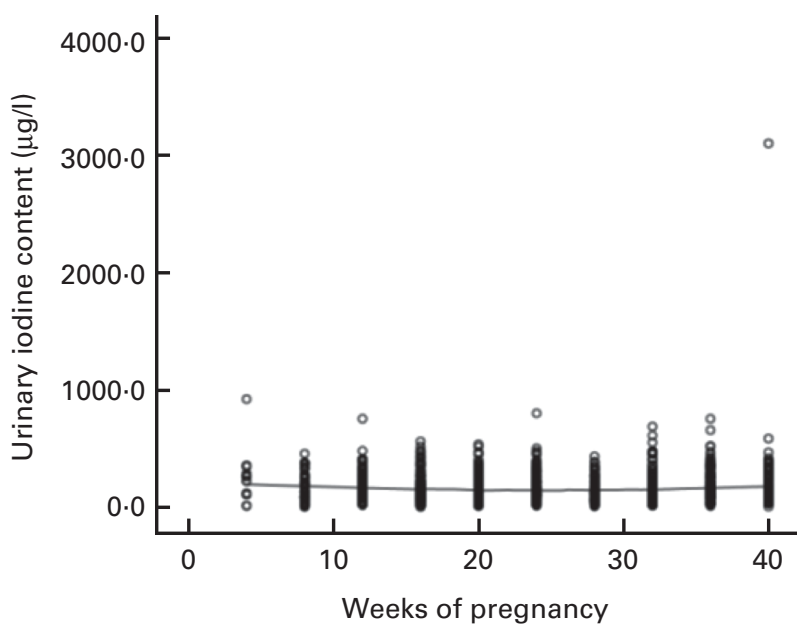

Fig. 1. Smooth line relationship of pregnant women's urinary iodine during every 4 weeks of pregnancy (LOESS analysis). 
Table 3. Median urinary iodine content (UIC) of pregnant women in three trimesters in thirty towns in Shijiazhuang City, September 2012

\begin{tabular}{lcccccc}
\hline & T1 $(\leq 13$ weeks $)$ & T2 $(14-26$ weeks $)$ & T3 $(\geq 27$ weeks $)$ & Total & Mann-Whitney $U$ & $P$ \\
\hline$n$ & 164 & 557 & 479 & 1200 & T1 v. T2: 23395 & 0.28 \\
UIC $(\mu \mathrm{g} / \mathrm{l})$ & 166 & 145 & 134 & 146 & T1 v. T3: 18265 & $0.04^{*}$ \\
IQR $(\mu \mathrm{g} / \mathrm{l})$ & $92-276$ & $83-248$ & $79-221$ & $88-239$ & T2 v. T3: 72462 & 0.41 \\
\hline
\end{tabular}

T1, first trimester; T2, second trimester; T3, third trimester; IQR, interquartile range (25-75\%).

\section{Correlation between pregnant and lactating women's} median urinary iodine content and median salt iodine

The one-sample Kolmogorov-Smirnov test found that the pregnant and lactating women's median UIC and MSI in the thirty towns were all normally distributed (the pregnant women's median UIC: $Z=0.818, P=0.516$; MSI: $Z=0.917$, $P=0.370$ and the lactating women's median UIC: $Z=0.805$, $P=0.536$; MSI: $Z=0.529, P=0.942$ ). Hence, the relationships between the pregnant and lactating women's median UIC and MSI in the thirty towns were analysed by linear regression. The linear regression analysis found that the pregnant women's median UIC did not correlate with MSI $(F=0.725$, $P=0 \cdot 402)$; however, the lactating women's median UIC was significantly linearly correlated with MSI $(F=8.513$, $P=0.007)$. The $R^{2}$ for MSI in the model was 0.233 , indicating that approximately $23.3 \%$ of the variability in lactating women's median UIC was associated with the variability in the MSI in the thirty towns. Scatter plots of median UIC and MSI of pregnant and lactating women in the thirty towns of Shijiazhuang city are provided in Figs. 3 and 4.

\section{Discussion}

The MWI in the thirty towns in the present study was less than $10 \mu \mathrm{g} / \mathrm{l}$, reconfirming the low iodine content in water in the rural areas of Shijiazhuang city. This low level implies that iodine consumption through water is not sufficient in this target community to meet dietary iodine needs. However, following the implementation of USI for 18 years, the coverage of adequately iodised salt in the thirty towns was above $90 \%$, and the MSI was about $30 \mathrm{mg} / \mathrm{kg}$, meeting the standards stipulated in the National Criteria for Elimination of Iodine Deficiency Disorders ${ }^{(22)}$. Under the current USI, the iodine nutrition of the general population (not including pregnant and lactating women) has met the WHO criteria in the rural areas of Shijiazhuang city ${ }^{(18)}$. However, according to the findings presented here, iodine intake for pregnant and lactating women in these rural areas is insufficient.

The median UIC of pregnant women in the first, second and third trimesters were 166, 145 and $134 \mu \mathrm{g} / \mathrm{l}$, respectively. When compared with the WHO's criteria, these results indicate no evidence of iodine deficiency in the first trimester of pregnancy, but possible iodine deficiency in the second and third trimesters. The median UIC in pregnant women decreased gradually from the first trimester onward, and their results indicate the borderline range, based on the UIC criteria derived from the WHO's recommended daily allowance during pregnancy. This finding is in accordance with the findings of previous studies which reported that the pregnant women's median UIC decreased as pregnancy advanced in mild iodine deficiency areas ${ }^{(25,26)}$.

The pregnant women's median UIC was found to be the highest in the first trimester, which could be accounted for

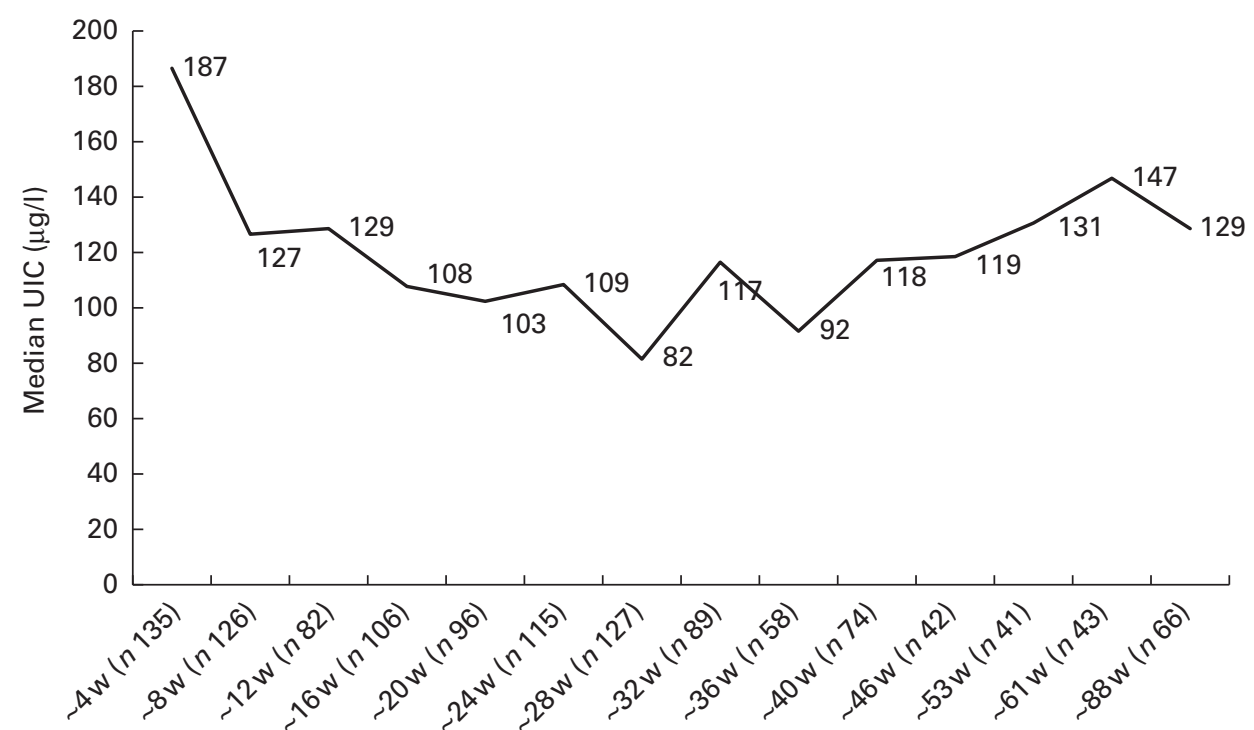

Fig. 2. Lactating women's median urinary iodine content (UIC) in every 4 weeks in thirty towns of Shijiazhuang City, Hebei Province, China, September 2012. w, Weeks. 


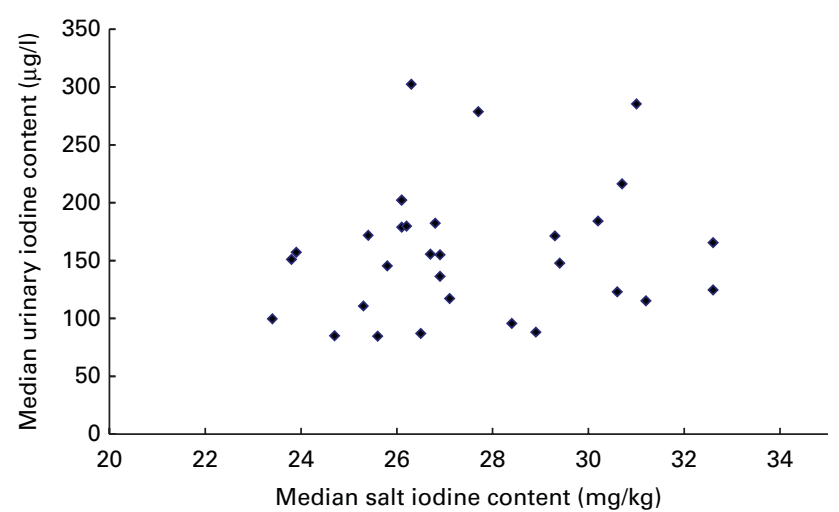

Fig. 3. Scatter plot of pregnant women's median urinary iodine content and median salt iodine content. (A colour version of this figure can be found online at http://www.journals.cambridge.org/bjn).

by the following factors. During the last month of the first trimester, pregnant women are more likely to recover from morning sickness, and eat more food than usual. They are also usually advised during their regular antenatal check-up to take more seafood containing high iodine content. Moreover, increased renal glomerular filtration caused by pregnancy can contribute to more iodine excretion in the urine ${ }^{(27)}$. These three points may be the key contributors to the highest median UIC during the first trimester observed in the present study.

In iodine deficient regions, as pregnancy advances, iodine stored in the thyroid is gradually depleted ${ }^{(11)}$, as was indicated by the gradual decrease of the pregnant women's median UIC during the second half of the second trimester and the third trimester in the present study. This has potentially serious implications in iodine deficient regions where starting iodine consumption is lower. Another possible factor playing some role in iodine deficiency could be the reduced ingestion of iodised salt. In general, starting from the second trimester, to avoid pregnancy-related complications like oedema and hypertension, pregnant women are advised to reduce their edible salt intake, and hence their iodine intake too was probably reduced in the present study. The finding that pregnant women's median UIC did not correlate with the MSI in their households could be attributed to the reduction of ingestion of iodised salt. However, such speculations are based on limited information about the pregnant women's iodised salt intake obtained during the field survey, with no formal survey of diet, and hence confirmation of these speculations requires well-designed objective studies on women's diet and iodine intake during gestation and lactation.

Based on LOESSS analysis of pregnant women's UIC for every 4 weeks, a lightly curved smooth line was established, which indicated that there was no substantial monthly change in pregnant women's median UIC. However, it is better to conduct a cohort study to clarify the monthly changes of pregnant women's median UIC.

In Hebei province, iodised salt is the key means to supplement iodine in iodine deficient populations, including pregnant and lactating women. No other special iodine supplement is offered to these particular populations. They are only encouraged to ingest more seafood, like seaweed, to get more iodine. Therefore, iodised salt plays an important role in pregnant women's iodine nutrition. Previous studies have illustrated that the iodine nutrition of the general population except for the pregnant group has reached a more than adequate level under the current universal iodised salt programme in China. For example, the median UIC in children aged $8-10$ years old is a little over $200 \mu \mathrm{g} / 1$ in Hebei province ${ }^{(28,29)}$. However, the present study observes that the current iodised salt programme may fail to provide sufficient iodine to the pregnant women in the rural areas of Shijiazhuang city. Perhaps, due to the limited iodised salt consumption during pregnancy or inadequate iodine content in the iodised salt, it could not provide sufficient iodine supplementation to the pregnant women in the present study area; this is a finding that has also been observed elsewhere in the world ${ }^{(13-16)}$. The Chinese cooking habit of deep-frying edible salt could also destroy the iodine content, and lead to some iodine loss in the cooking process. The kind of salt used by commercial food manufacturers (e.g. of soya sauce, pickles, etc.) also deserves to be considered as a reason why the USI strategy may not provide sufficient iodine to pregnant women. Reports from China suggest that commercial food manufacturers do not typically use iodised salt, despite the legislation of 'universal'. The iodine contents of foods taken by these pregnant women and of the salt ingredient of the most commonly used commercial food products, which were outside the scope of the present survey, can be taken up for further research studies.

The Chinese family planning policy forbids more than a child for a couple. Consequently many women who are expecting their second or third child tend to hide their pregnancy. It is a major limitation that such pregnant women could not be included in the present study, as the selection of the sample was confined to pregnancies registered at the town hospital.

A clear finding is that pregnant women of the sample of the present study area do not receive sufficient iodine in the

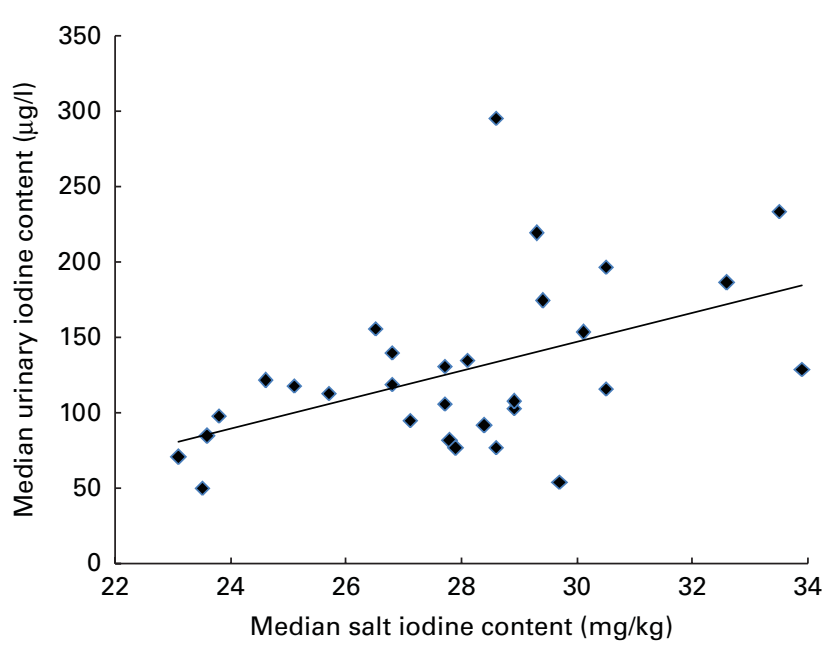

Fig. 4. Positive correlation between lactating women's median urinary iodine and median salt iodine in thirty towns of Shijiazhuang city, Hebei Province, China, September 2012. (A colour version of this figure can be found online at http://www.journals.cambridge.org/bjn). 
second and third trimesters of their pregnancy; it would be reasonable to presume that the same is true of the entire population of the study area. In response, the following potential corrective measures could be implemented to address this issue. Firstly, we need to increase the iodine content in the iodised salt, but the beneficial effects of this step depend on the whims and quantities of its consumption. Secondly, iodine loss through deep-frying of iodised salt could be minimised through awareness campaigns. The third measure, which is popular in many parts of the world ${ }^{(1,30)}$, is to provide extra iodine for pregnant women using supplements, such as multiple micronutrient tablets containing iodine. However, world-wide experience of the advocacy of iodine-containing supplements is still poor, as high coverage rates of prenatal supplements have not been achieved even in resource-rich countries. Given the high variation of urinary iodine, it is not practical to identify the degree of iodine deficiency in individual cases of women before supplementation. Hence, this measure should be implemented with caution.

The overall median UIC in lactating women was a little higher than the WHO-recommended level, suggesting that there was no iodine deficiency during lactation in the rural areas of Shijiazhuang city. However, given that over $40 \%$ of lactating women's UIC was below $100 \mu \mathrm{g} / \mathrm{l}$, and the median UIC was less than $100 \mu \mathrm{g} / \mathrm{l}$ during some weeks (e.g. 25-28 and 33-36), some lactating women could be at risk of mild iodine deficiency, and breastfeeding babies may not be getting enough iodine from their mothers' milk. The highest median UIC was found in the first 4 weeks of lactation. This could be explained by the extra dermal iodine exposure from disinfectants during labour in the hospital.

Given the extremely low iodine content in drinking water, it is not considered a significant contributor to the pregnant and lactating women's iodine nutrition. Hence, no further analysis of MWI was undertaken. Only the correlation between MSI and the pregnant and lactating women's median UIC was analysed in the present study. The lactating women's median UIC was linearly correlated with the MSI in their households. This suggests that iodised salt had successfully supplemented iodine in the lactating women, and was an effective means to provide iodine. However, given that the overall median UIC in the lactating women was relatively low, and that the UIC was lower than the WHO criterion during certain lactation periods, it is reasonable to suggest that extra iodine supplementation might be necessary for lactating mothers too.

\section{Conclusions}

Owing to the implemention of USI, the iodine nutrition of the general population in the rural areas of Shijiazhuang city is at a healthy level, and this is indicated by the median UIC of children aged 8-10 years. However, the iodine nutrition of pregnant and lactating women, which is critical for children's cognitive development, had not been previously examined. The present study was an extensive survey on the iodine nutrition status of these target populations in the rural areas of Shijiazhuang city, undertaken for the first time in Hebei province. The findings of the study suggest that the current
USI programme provides adequate iodine for lactating women, but may have failed to provide adequate iodine supplementation to pregnant women, possibly due to the influence of limited iodised salt intake during pregnancy. As an alternative corrective measure, supplementing the diet with a multiple micronutrient pill containing iodine should be carefully considered for both pregnant and lactating women, in order to address the needs of the 1000 critical days of a child in which changes can be made to improve growth and brain development.

\section{Acknowledgements}

The authors thank profusely the staff in the Endemic Control Department of the CDC of each of the eighteen counties for their assistance in the field investigation of the present study.

The present study did not receive any specific grant from commercial or not-for-profit sectors. No industry provided the present investigation with free or concessional medications, equipment, kits or reagents or statistical analysis.

The authors declare that there are no conflicts of interest.

The authors' contributions are as follows: H. Z. was responsible for the study design, field investigation and laboratory detection of iodine. S. L. did the data analysis and paper writing. Z. M. took part in the field investigation and laboratory detection. W. L. entered the data for analysis. X. Z. and Y. W. took part in the laboratory analyses. S. R. was responsible for the revision of the paper and language editing. All the authors read and approved the final version of the paper.

\section{References}

1. Pearce EN (2009) What do we know about iodine supplementation in pregnancy? J Clin Endocrinol Metab 94, 3188-3190.

2. Younes-Rapozo V, Berendonk J, Savignon T, et al. (2006) Thyroid hormone deficiency changes the distribution of oligodendrocyte/myelin markers during oligodendroglial differentiation in vitro. Int J Dev Neurosci 24, 445-453.

3. Zimmermann MB (2009) Iodine deficiency in pregnancy and the effects of maternal iodine supplementation on the offspring: a review. Am J Clin Nutr 89, 668-672.

4. World Health Organization (2014) Guideline: Fortification of Food-grade Salt with Iodine for the Prevention and Control of Iodine Deficiency Disorders. Geneva: WHO.

5. Bath SC, Steer CD, Golding J, et al. (2013) Effect of inadequate iodine status in UK pregnant women on cognitive outcomes in their children: results from the Avon Longitudinal Study of Parents and Children (ALSPAC). Lancet 382, 331-337.

6. Henrichs J, Bongers-Schokking JJ, Schenk JJ, et al. (2010) Maternal thyroid function during early pregnancy and cognitive functioning in early childhood: the generation R study. $J$ Clin Endocrinol Metab 95, 4227-4234.

7. Vermiglio F, Lo Presti VP, Moleti M, et al. (2004) Attention deficit and hyperactivity disorders in the offspring of mothers exposed to mild-moderate iodine deficiency: a possible novel iodine deficiency disorder in developed countries. J Clin Endocrinol Metab 89, 6054-6060.

8. Delange F (2000) Endemic cretinism. In The Thyroid, pp. 743-754 [LE Braverman and RD Utiger, editors]. Philadelphia, PA: Lippincott.

9. Zimmermann MB (2009) Iodine deficiency. Endocr Rev 30, $376-408$. 
10. World Health Organization (2007) Assessment of Iodine Deficiency Disorders and Monitoring their Elimination. A Guide for Programme Managers, 3rd ed. Geneva: WHO.

11. Glinoer D (2001) Pregnancy and iodine. Thyroid 11, 471-481.

12. Leung AM, Pearce EN \& Braverman LE (2011) Iodine nutrition in pregnancy and lactation. Endocrinol Metab Clin North Am 40, 765-777.

13. Andersen SL, Sørensen LK, Krejbjerg A, et al. (2013) Iodine deficiency in Danish pregnant women. Dan Med J 60, A4657.

14. Sultanalieva RB, Mamutova S \& van der Haar F (2010) The current salt iodization strategy in Kyrgyzstan ensures sufficient iodine nutrition among school-age children but not pregnant women. Public Health Nutr 13, 623-630.

15. Gowachirapant S, Winichagoon P, Wyss L, et al. (2009) Urinary iodine concentrations indicate iodine deficiency in pregnant Thai women but iodine sufficiency in their school-aged children. J Nutr 139, 1169-1172.

16. Fisher J, Tran T, Biggs B, et al. (2011) Iodine status in late pregnancy and psychosocial determinants of iodized salt use in rural northern Viet Nam. Bull World Health Organ 89, 813-820.

17. Yan YQ, Chen ZP, Yang XM, et al. (2005) Attention to the hiding iodine deficiency in pregnant and lactating women after universal salt iodization: a multi-community study in China. J Endocrinol Invest 28, 547-553.

18. Zhang HH, Li WH, Di XY, et al. (2011) Survey on the iodine nutrition status of children aged 8-10 years in Shijiazhuang city in 2009. Chin J Endem Dis 26, 276-277 (in Chinese).

19. World Health Organization (1994) Indicators for Assessing Iodine Deficiency Disorders and their Control Through Salt Iodization. Geneva: WHO/UNICEF/ICCIDD.
20. Pino S, Fang SL \& Braverman LE (1998) Ammonium persulfate: a new and safe method for measuring urinary iodine by ammonium persulfate oxidation. Exp Clin Endocrinol Diabetes 106, 22-27.

21. State Bureau of Quality and Technical Supervision (1999) General Test Method in Salt Industry - Determination of Iodide Ion. Beijing: SBQTS (in Chinese).

22. Ministry of Health (2008) Criteria for Elimination of Iodine Deficiency Disorders. Beijing: MOH (in Chinese).

23. Ministry of Health (2006) The Standard Test Method for Drinking Water. Beijing: MOH (in Chinese).

24. Ministry of Health (1995) Criteria for Classification of Endemic Areas of Iodine Deficiency Disorders. Beijing: $\mathrm{MOH}$ (in Chinese).

25. Ainy E, Ordookhani A, Hedayati M, et al. (2007) Assessment of intertrimester and seasonal variations of urinary iodine concentration during pregnancy in an iodine-replete area. Clin Endocrinol (Oxf) 67, 577-581.

26. Brander L, Als C, Buess H, et al. (2003) Urinary iodine concentration during pregnancy in an area of unstable dietary iodine intake in Switzerland. J Endocrinol Invest 26, 389-396.

27. Glinoer D (2007) The importance of iodine nutrition during pregnancy. Public Health Nutr 10, 1542-1546.

28. Lv SM, Xie LJ, Zhou RH, et al. (2009) Control of iodine deficiency disorders following 10-year universal salt iodization in Hebei province of China. Biomed Environ Sci 22, 472-479.

29. Lv SM, Ma J, Du YG, et al. (2013) Analysis on the results of IDD surveillance in Hebei province in 2011. Chin J Endemiol 32, 64-66 (in Chinese).

30. Zimmermann M \& Delange F (2004) Iodine supplementation of pregnant women in Europe: a review and recommendations. Eur J Clin Nutr 58, 979-984. 